\title{
Is Alacrima So Prevalent in Patients With Early-Onset Achalasia?
}

TO THE EDITOR: Genetic factors have been suggested to play an important role in the development of achalasia, and various candidate genes have been documented. ${ }^{1}$ ALADIN is one of the candidate genes. However, the study by Di Nardo et $\mathrm{al}^{2}$ has shown that no pathogenic mutations were detected in the ALADIN gene of 41 patients with isolated achalasia. In addition, Allgrove syndrome is a rare disorder, and achalasia is usually present in infancy, despite of one case report with adult-onset disease. $^{1,3}$

The study by Jung et al ${ }^{4}$ itself was very well-designed and well-organized to investigate genetic predisposition as the cause of achalasia. The authors tried to selectively enroll patients with early-onset disease and accompanying alacrimia in order to increase the possibility of detecting genetic abnormality in the ALADIN gene. This contrasted the design of the study by Di Nardo et $\mathrm{al}^{2}$ in which analyzed patients with a wider range of age. ${ }^{4}$ After they opened the "Aladdin's magic lamp," however Jung and his colleagues found that "the genie in the lamp" did not exist, despite of their appropriate plan and great effort. In other words, no mutations were detected in the genes of the selected patients with early-onset disease and accompanying alacrimia.

Herein, I have 2 trivial points to discuss with Jung and his colleagues. They reported that the prevalence of alacrima is as high as $42 \%$ in patients with early-onset achalasia. ${ }^{4}$ In their study, the cut-off value for alacrima was defined as $10 \mathrm{~mm} / 5 \mathrm{~min}$ with the Schirmer I test (without anesthesia) according to the reference. ${ }^{4,5}$ However, the cited reference showed that the recommended cut-off value for dry eye with the Schirmer I test is 5 $\mathrm{mm} / 5 \mathrm{~min}^{5}$ Therefore, the study by Jung et $\mathrm{al}^{4}$ might overestimate the prevalence of alacrima using, without documented reason, a cut-off value higher than the one recommended in the cited test. Instead I consider that the authors should estimate the prevalence by using the recommended cut-off value of $5 \mathrm{~mm} / 5$ min. Additionally, in the study by Verma et al, ${ }^{6}$ the Schirmer test was performed with anesthesia with the $5 \mathrm{~mm} / 5 \mathrm{~min}$ cut-off value of alacrimia. Therefore, I consider that the $20 \%$ prevalence of alacrimia reported in the study of Verma et $\mathrm{al}^{6}$ should not be directly compared with findings from the study of Jung et al. ${ }^{4}$

Nevertheless, Jung et $\mathrm{al}^{4}$ have established an excellent cohort of early-onset achalasia, and I expect them to detect novel genetic factors, should they decide to continue investigation of genes responsible for development of achalasia, different from the ALADIN gene.

Hee Man Kim

Department of Internal Medicine Kwandong University College of Medicine Myongji Hospital, Goyang, Gyeonggi-do, Korea

1. Gockel HR, Schumacher J, Gockel I, Lang H, Haaf T, Nöthen MM. Achalasia: will genetic studies provide insights? Hum Genet 2010;128:353-364.

2. Di Nardo G, Tullio-Pelet A, Annese V, et al. Idiopathic achalasia is not allelic to alacrima achalasia adrenal insufficiency syndrome at the ALADIN locus. Dig Liver Dis 2005;37:312-315.

3. Gilio F, Di Rezze S, Conte A, et al. Case report of adult-onset Allgrove syndrome. Neurol Sci 2007;28:331-335.

4. Jung KW, Yoon IJ, Kim DH, et al. Genetic evaluation of ALADIN gene in early-onset achalasia and alacrima patients. J Neurogastroenterol Motil 2011;17:169-173.

5. Methodologies to diagnose and monitor dry eye disease: report of the Diagnostic Methodology Subcommittee of the International Dry Eye WorkShop (2007). Ocul Surf 2007;5:108-152.

6. Verma S, Brown S, Dakkak M, Bennett JR. Association of adult achalasia and alacrima. Dig Dis Sci 1999;44:876-878.

\section{Conflicts of interest: None.}

